\title{
Comparison of ohmic contact formation of titanium and zirconium on boron doped diamond
}

\author{
V. Mortet ${ }^{1,2}$, A. Taylor ${ }^{1}$, M. Davydova ${ }^{1}$, L. Fekete$^{1}$, Z. Vlčková Živcováa ${ }^{3}$ L. Klimša ${ }^{1}$, N. \\ Lambert $^{1}$, P. Hubík ${ }^{1}$, D. Trémouilles ${ }^{4}$, A. Soltani ${ }^{5}$ \\ ${ }^{1}$ Institute of Physics of the Czech Academy of Sciences, Na Slovance 2, 18221 Prague 8, Czech Republic \\ ${ }^{2}$ Czech Technical University, Faculty of Biomedical Engineering, Sportovců 2311, 27201 Kladno, Czech \\ Republic
}

${ }^{3}$ J. Heyrovsky Institute of Physical Chemistry of the Czech Academy of Sciences, Dolejškova 3, 18223

Prague 8, Czech Republic

${ }^{4}$ LAAS-CNRS, Université de Toulouse, CNRS, 7 Avenue du Colonel Roche, 31400 Toulouse, France

${ }^{5}$ LN2, Université de Sherbrooke, 3000 Boul. de l'Universite, Sherbrooke J1K 0A5, Canada

With a high affinity to carbon comparable to titanium and an electrically conductive carbide, zirconium has potential to form ohmic contact on boron doped diamond. In this work, formation of ohmic contacts on boron doped diamond using zirconium is studied in comparison to titanium. Boron doped diamond epitaxial layers have been grown by microwave plasma enhanced chemical vapour deposition with various B/C ratio. Circular Transmission Line Model structures were fabricated using standard micro-fabrication technologies. Specific contact resistance of fabricated contacts was determined for different boron concentrations and for various annealing temperatures. Ohmic contact using zirconium are form after annealing at $400{ }^{\circ} \mathrm{C}$. Specific contact resistance steadily decreases with high temperature annealing down to a value of ca. $1 \mathrm{~m} \Omega . \mathrm{cm}^{2}$ after annealing at $700{ }^{\circ} \mathrm{C}$ for highly boron doped diamond. In comparison, titanium contact fabricated on highly doped diamond appears not stable under high temperature annealing.

\section{INTRODUCTION}

Its extraordinary properties have made diamond a promising material for fabrication of novel power electronic devices. Stable ohmic contacts with a low specific contact resistance are crucial in the fabrication of power electronic devices. Properties of ohmic contacts are determined by many parameters: the crystalline orientation, the nature of the metal, the doping level, the surface pre-treatment and the annealing process [1,2]. Many carbide forming metals have been studied for the formation of ohmic contact on doped diamond. Despite its possible use for Schottky contact formation [3], the high 
affinity to carbon of zirconium to form electrically conductive carbide [4] highlights its potential for ohmic contact formation. In this study, we compare the formation and the properties of ohmic contact on boron-doped diamond (BDD) using zirconium and titanium. Epitaxial BDD layers were grown by microwave plasma enhanced chemical vapour deposition (MW-PECVD) with various boron concentrations. The morphology and crystal structure of the diamond layers were characterized by scanning electron microscopy (SEM), atomic force microscopy (AFM) and Raman spectroscopy. Metals contacts were fabricated using standard micro-fabrication technologies. Specific contact resistance was investigated using the circular Transmission Line Model (c-TLM) [5] after consecutive annealing processes.

\section{EXPERIMENTAL DETAILS}

Epitaxial BDD layers were grown on synthetic diamond crystals in an AX5010 MW-PECVD reactor using a methane, hydrogen and trimethylborane gas mixture. The boron to carbon ratios (B/C) was varied from $500 \mathrm{ppm}$ up to 20,000 ppm (see Table I). All layers were grown on (100) oriented substrates apart from layers with $B / C=20,000 \mathrm{ppm}$ which were grown on (111) oriented substrates. Deposition process parameters are reported in Table II. Prior to and after deposition, diamond samples were cleaned in a hot mixture of $\mathrm{H}_{2} \mathrm{SO}_{4}$ and $\mathrm{KNO}_{3}$, rinsed in DI-water, ultrasonically cleaned in acetone and isopropyl alcohol and finally dried using filtered compressed air.

The morphology and structure of deposited layers was characterized by using a Tescan FERA3 SEM, AFM, and Raman spectroscopy. AFM measurements were carried out on an ambient Dimension Icon (Bruker) in Peak Force Tapping mode with ScanAsyst Air tips (Bruker). Raman spectroscopy measurements were carried out using a Labram HR spectrometer (Horiba Jobin-Yvon) interfaced to an Olympus microscope (objective 100x) equipped with a $50 \mu \mathrm{m}$ confocal hole and a He-Ne laser $633 \mathrm{~nm}$ with $8 \mathrm{~mW}$ power.

c-TLM structures, i.e. circular electrodes $(150 \mu \mathrm{m}$ in diameter $)$ with the outer electrodes varying between 10 and $60 \mu \mathrm{m}$, were patterned by the lift-off technique using a positive photoresist ma- P 1210 (Micro Resist technologies). The resit was exposed using a laser writer Microwriter ML (Lot Oriel). $10 \mathrm{~nm}$ thick titanium and zirconium contacts were deposited by electron beam evaporation (Edward Auto 500) and protected from oxidation by a $90 \mathrm{~nm}$ thick gold layer with a $10 \mathrm{~nm}$ thick platinum inter-diffusion layer. Contacts were consecutively annealed at $200{ }^{\circ} \mathrm{C}, 400{ }^{\circ} \mathrm{C}, 500{ }^{\circ} \mathrm{C}, 600^{\circ} \mathrm{C}$ and $700{ }^{\circ} \mathrm{C}$ in nitrogen at low pressure for $20 \mathrm{~min}$ in a rapid thermal annealing system (AS-One from Annealsys). From room temperature up to $200{ }^{\circ} \mathrm{C}$, the resistance of fabricated c-TLM structures was determined from linear least squares fitting of their I-V characteristic measured using a computer controlled Agilent 4142B modular DC source/monitor and a probe station Suss Microtech PA-20. Specific contact resistance and diamond resistivity were determined using c-TLM, i.e. from linear least squares fitting of total resistance corrected for circular geometry vs electrodes gap spacing [5].

Table I. Specific contact resistance ( $\rho_{c}$ ) of zirconium (right) and titanium (left) contacts, and boron doped diamond layers' resistivity as function of B/C ration in gas phase during MW-PECVD deposition

\begin{tabular}{|c|c|c|c|c|c|}
\hline B/C ratio & $\mathbf{5 0 0} \mathbf{~ p p m}$ & $\mathbf{2 , 0 0 0} \mathbf{~ p p m}$ & $\mathbf{6 , 0 0 0} \mathbf{~ p p m}$ & $\mathbf{2 0 , 0 0 0} \mathbf{~ p p m}$ & Units \\
\hline Resistivity & 6.5 & 13.5 & 12 & 84 & $\Omega . \mathrm{cm}$ \\
\hline$\rho_{\mathrm{c}}\left(400^{\circ} \mathrm{C}\right)$ & $996 / 1.7$ & $54 / 1.0$ & $38 / 0.37$ & $2 / 0.09$ & $\mathrm{~m} \Omega . \mathrm{cm}^{2}$ \\
\hline$\rho_{\mathrm{c}}\left(700^{\circ} \mathrm{C}\right)$ & $267 / 1.7$ & $1.1 / 0.8$ & $1.5 / 0.7$ & $0.7 / 3.7$ & $\mathrm{~m} \Omega . \mathrm{cm}^{2}$ \\
\hline
\end{tabular}




\begin{tabular}{|c|c|c|c|c|c|}
\hline $\begin{array}{c}\text { Substrate } \\
\text { orientation }\end{array}$ & $\begin{array}{c}\text { Microwave } \\
\text { power(W) }\end{array}$ & $\begin{array}{c}\text { Pressure } \\
\text { (mbar) }\end{array}$ & $\begin{array}{c}\text { CH4 } \\
\text { concentration }\end{array}$ & Substrate temperature & Deposition time \\
\hline$(100)$ & 700 & 100 & $1 \%$ & $1100{ }^{\circ} \mathrm{C}$ & $1 \mathrm{~h}$ \\
\hline$(111)$ & 575 & 60 & $0.1 \%$ & $1000{ }^{\circ} \mathrm{C}$ & $1 \mathrm{~h}$ \\
\hline
\end{tabular}

\section{RESULTS AND DISCUSSION}

Figure 1 shows the surface morphology of fabricated epitaxial layers as observed by scanning electron microscopy and atomic force microscopy. The surface of epitaxial layers is very smooth and free of frequently observed four-fold symmetry hillocks or non-
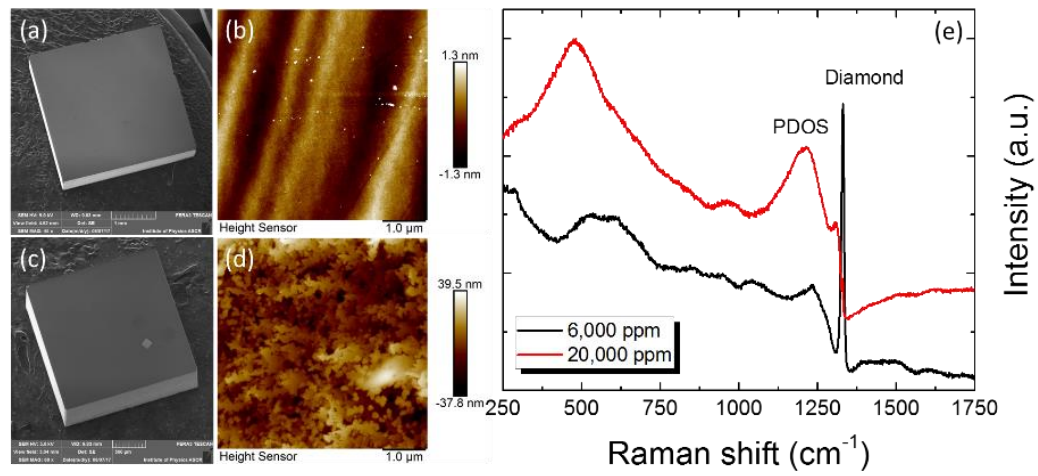

epitaxial grains. The surface morphology was further characterized by atomic force microscopy. The surface of (100) boron doped epitaxial layers is very smooth with root mean square roughness below $1 \mathrm{~nm}$, typically $0.5 \mathrm{~nm}$ on a $25 \mu \mathrm{m}^{2}$ area. The surface of (111) is rougher with an average roughness of $10.8 \mathrm{~nm}$ and a dendritic like surface morphology. Except for the layer grown with a B/C ratio of $500 \mathrm{ppm}$, Raman spectra of epitaxial layers exhibit characteristic peaks of highly boron doped diamond with metallic conductivity (see figure 1e), i.e. a red shifted diamond peak position with a Fano shape, additional bands, at ca. $500 \mathrm{~cm}^{-1}$ and ca. $1230 \mathrm{~cm}^{-1}$. Small structures at $610 \mathrm{~cm}^{-1}$ and 1050 $\mathrm{cm}^{-1}$ attributed to boron-carbon vibrations and carbon vibrations [6] are observed on layers grown on (100) oriented substrates with lower boron concentrations. While the origin of the wide band at $500 \mathrm{~cm}^{-1}$ remains an open question, the peak at $1230 \mathrm{~cm}^{-1}$ has been recently attributed to a Fano-shaped diamond maximum phonon density of states [6].

Figure 1. Scanning electron microscopy (a, c) and atomic force microscopy images (b, d) of boron doped diamond epitaxial layers grown on (100) oriented (a, b) and (111) oriented (c,d) HPHT diamond substrates. (e) Comparison of Raman spectra of epitaxial boron doped diamond layer grown at $\mathrm{B} / \mathrm{C}$ ratio of $6,000 \mathrm{ppm}$ and 20,000 ppm.

Figure 2 compares the current voltage (I-V) characteristics measured at room temperature of a $35 \mu \mathrm{m}$ gap c-TLM test structure of titanium and zirconium contacts on doped diamond layers deposited with various $\mathrm{B} / \mathrm{C}$ ratio after different annealing processes: after metal deposition, i.e. no annealing (Fig. 2a), after annealing at $400{ }^{\circ} \mathrm{C}$ (Fig. 2b) and after annealing at $700{ }^{\circ} \mathrm{C}$ (Fig. 2c). As measured characteristics are symmetric, to ease comparison of the two metals' contact characteristics: zirconium contact characteristics on the negative half side and titanium contact characteristics on the positive half side are displayed. Noticeably, I-V characteristics of titanium contacts are ohmic for as deposited contacts and annealed contacts for all doped layers studied in this work. In contrary, I-V characteristics of as deposited zirconium contacts are not linear and annealing at $400{ }^{\circ} \mathrm{C}$ is 
necessary to obtain ohmic contacts. Taken into account comparable thickness of all studied layers, the observed higher total resistance, i.e. lower slope, of the c-TLM test structure fabricated on the doped diamond layer grown at $\mathrm{B} / \mathrm{C}=20,000 \mathrm{ppm}$ compared to the one grown at $\mathrm{B} / \mathrm{C}=6,000 \mathrm{ppm}$ is due to the generally observed higher resistivity of boron doped layers grown on (111) oriented substrates [7]. Average resistivity of doped diamond layers calculated using the circular Transmission Line Model are reported in table I. The evolution of the calculated specific contact resistance of titanium and zirconium contacts
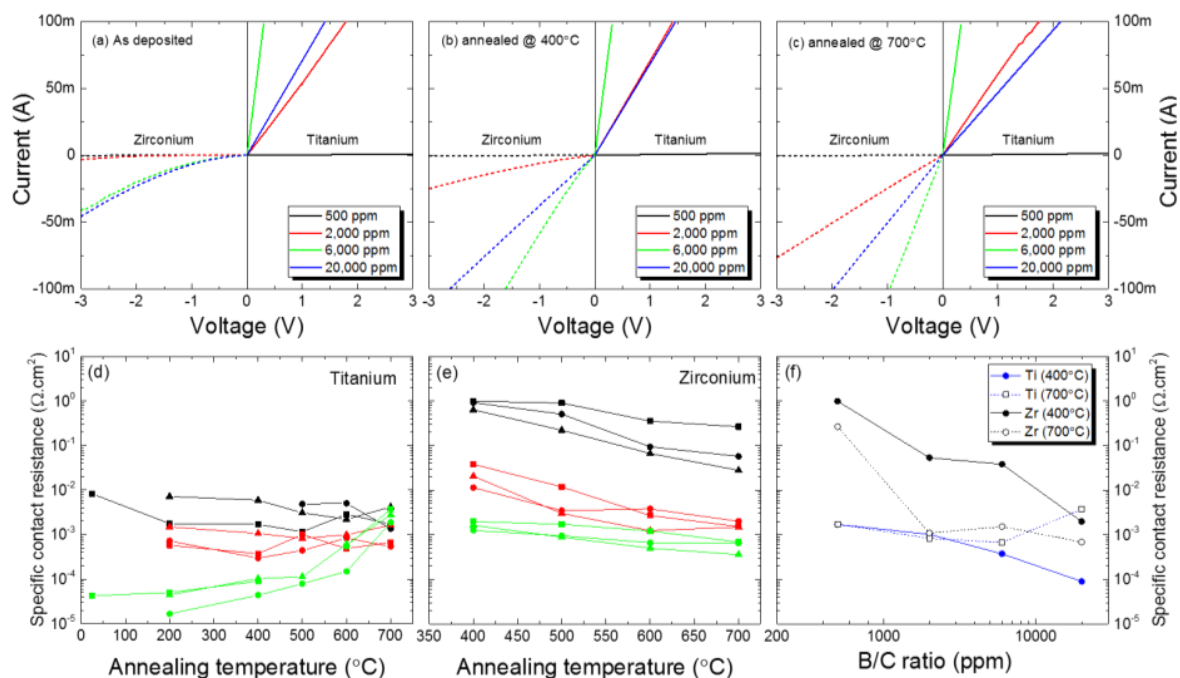

as a function of measurement temperature, annealing temperature and $\mathrm{B} / \mathrm{C}$ ratio is reported in figure $2 \mathrm{~d}$-e. These figures clearly show that specific contact resistance scales with boron doping. High temperature annealing further decreases the specific contact resistance of zirconium contact whereas it increases the one of titanium contact for $\mathrm{B} / \mathrm{C}$ ratio higher than $6,000 \mathrm{ppm}$. This instability of titanium contact, already reported, seems to affect only highly doped diamond layers [8]. The larger specific contact resistances compared to values from the [9] might be attributed to the absence of an amorphisation process prior to the metal deposition in the contact fabrication process.

Figure 2. Room temperature I-V characteristics of c-TLM structure with $35 \mu \mathrm{m}$ gap of titanium (solid curve) and zirconium (dash curve) contacts as a function of $\mathrm{B} / \mathrm{C}$ ratio after different thermal treatment: (a) as deposited, (b) after $400^{\circ} \mathrm{C}$ annealing and (c) after $700^{\circ} \mathrm{C}$ annealing. Evolution of the titanium (d) and zirconium (e) specific contact resistance as a function of annealing temperature for $\mathrm{B} / \mathrm{C}$ ratio of $500 \mathrm{ppm}$ (black), 6,000 ppm (red), 20,000 ppm (green) and the contact resistance measurement's temperature: $25{ }^{\circ} \mathrm{C}$ (squares), $120{ }^{\circ} \mathrm{C}$ (circles) and $200{ }^{\circ} \mathrm{C}$ (triangle). (f) Comparison of the specific contact resistance of titanium and zirconium contacts as a function of B/C between annealing at $400{ }^{\circ} \mathrm{C}$ and 700 ${ }^{\circ} \mathrm{C}$.

\section{CONCLUSION}

Zirconium contacts on boron doped homo-epitaxial diamond layers were studied for different boron doping and annealing temperatures in comparison with titanium contacts. Zirconium ohmic contacts are formed after annealing at temperatures above 400 ${ }^{\circ} \mathrm{C}$. Resistivity values determined from c-TLM are consistent with data from the literature. Calculated specific contact resistance of zirconium contacts are higher than titanium 
contacts, however, zirconium contacts show superior thermal stability following high temperature annealing $\left(>600{ }^{\circ} \mathrm{C}\right)$ for highly boron doped diamond layers $(\mathrm{B} / \mathrm{C} \geq 6,000$ ppm).

\section{AKNOWLEDGEMENT}

This work was financially supported by the project 17-05259S of Czech Science Foundation, the French-Czech Project Barrande 35785SC - 7AMB16FR004 of the Czech Ministry of Education, Youth and Sports, the MEYS CR FUNBIO CZ.2.16/3.1.00/21568 (SEM purchase), LO1409, LM2015088 projects (SEM maintenance) and the J.E. Purkyně fellowship awarded to V. Mortet by the Czech Academy of Sciences.

\section{REFERENCES}

1. Y. Koide, M. Yokoba, A. Otsuki, F. Ako, T. Oku, M. Murakami, Diamond Relat. Mater. 6, 847 (1997).

2. K. Das, V. Venkatesan, K. Miyata, D.L. Dreifus, J.T. Glass, Thin Solid Films 212, 19 (1992).

3. M. Suzuki, T. Sakai, T. Makino, H. Kato, D. Takeuchi, M. Ogura, H. Okushi, S. Yamasaki, Phys. Status Solidi 210, 2035 (2013).

4. S.R. Shatynski, Oxid Met. 13, 105 (1979).

5. J.H. Klootwijk, C.E. Timmering, Merits and limitations of circular TLM structures for contact resistance determination for novel III-V HBTs, Proc. 2004 Int. Conf. Microelectron. Test Struct. 17, 8 (2004).

6. V. Mortet, Z. Vlčková Živcová, A. Taylor, O. Frank, P. Hubík, M. Davydova et al. Refined analysis of boron doped diamond Raman spectrum. $28^{\text {th }}$ International Conference on Diamond and Carbon Materials, Gothia Towers, Gothenburg, Sweden.

7. V. Mortet, J. Pernot, F. Jomard, A. Soltani, Z. Remes, J. Barjon, J. D’Haen, K. Haenen, Diamond Relat. Mater. 53, 29 (2015).

8. C. Johnston, P.R. Chalker, I.M. Buckley-Golder, M. van Rossum, M. Werner, E. Obermeier, Mater Sci Eng B. 29, 206 (1995).

9. J. Nakanishi, A. Otsuki, T. Oku, O. Ishiwata, M. Murakami, J. Appl. Phys. 76, 2293 (1994). 